\title{
Developing the Team While Travelling: Infusing Elements of High Impact Practices into a Study Abroad Course for Student-Athletes
}

\author{
Christopher R. Leupold, Ph.D. \\ Elon University \\ Anthony G. Weaver, Ph.D. \\ Elon University \\ Eric H. Hall, Ph.D. \\ Elon University
}

\begin{abstract}
Undergraduate institutions today are increasingly looking to adopt high impact practices (HIP) as a means to provide optimal learning experiences for their students. Study abroad courses are a particularly popular HIP offering for students, as they provide opportunities to not only experience new cultures around the world, but also to gain insights into their own cultural identities. Unfortunately, because of the many demands placed on Division I collegiate studentathletes, they are often not able to engage in such global experiences. This case study describes a credit-bearing, short-term study abroad course that not only taught Division I volleyball studentathletes how to study culture at the individual, team, and national levels; it also served as a simultaneous organization development intervention designed to improve student-athletes' individual and team effectiveness. These student-athletes were introduced to models and theories of culture and were engaged in a variety of individual- and team-based experiential activities and characteristic of effective HIPs. Elements were infused to make the course more personally relevant and meaningful to the student-athletes, including individual assessments to gain insights into their cultural identities, formal assessments of the team's dynamics, and team-based activities and workshops that addressed the team's weakest areas related to performance. This case study is an example of how an innovative course can be created to not only provide a study abroad opportunity for student-athletes, but also be tailored to address individual players' and team needs, thus creating a positive and lasting experience for all involved.
\end{abstract}

Keywords: study abroad, culture, engaged learning, high-impact practices, team development, organization development 


\section{High Impact Practices, Study Abroad, and Student-Athletes}

Since the Boyer Commission's (1998) call for a "new model of educating at undergraduate research universities" and the ongoing initiative by the Association of American Colleges and Universities' (AAC\&U) Liberal Education and America's Promise (LEAP), participation in high impact practices (HIPs) has steadily increased as institutions recognize the many benefits they bring to students. HIPs are teaching practices and learning experiences that typically "demand considerable time and effort, facilitate learning outside of the classroom, require meaningful interactions with faculty and other students, encourage collaboration with diverse others, and provide frequent and substantive feedback" (National Survey of Student Engagement, 2017, p. 2). Currently, the AAC\&U lists 11 different high impact practices that students may experience during their time in college: first-year seminars, common intellectual experiences, learning communities, writing-intensive courses, collaborative assignments, undergraduate research, service learning, internships, electronic portfolios, capstone projects, and diversity/global learning experiences. The many positive outcomes for participants have been documented to include: enhanced critical thinking (Kuh, 2008; Pascarella \& Blaich, 2013), increases in academic achievement (Cole \& Espinoza, 2008; Kilgo, Ezell-Sheets, \& Pascarella, 2015), increases in student retention rates (Nagda, Gregerman, Jonides, von Hippel, \& Lerner, 1998), and a high overall levels of students' satisfaction with learning (Bauer \& Bennett, 2008).

Successful implementation of HIPs poses many challenges. To be most beneficial, HIPs require an extensive amount of time and resources from the student, the faculty mentor, and the institution (Linn, Palmer, Baranger, Gerard, \& Stone, 2015). Kilgo et al. (2015) also point out that, while research shows that all students may benefit from participating in HIPs, not all students participate at the same rate. Although there is a rapidly growing body of research on student participation in HIPs and the benefits and concerns for those involved, there is limited work that examines the participation and experience of a particular underrepresented subgroup - studentathletes. In addition to the usual challenges (i.e., financial costs, lack of discretionary time, schedule conflicts, etc.) that may limit student participation in HIPs, student-athletes face additional unique barriers that often severely hinder their access to them (Gayles, 2009; Potuto \& O'Hanlon, 2007). Balancing their many athletic commitments (e.g., year-round practice and training schedules, traveling for competitions, and frequent team meetings) along with the additional time and effort required for any meaningful HIP experience can make it even more difficult for a student-athlete to participate. One HIP that has often proven particularly challenging to provide to student-athletes is a global experience through a study abroad program. Based on findings from the 2015 NCAA GOALS study, $10 \%$ of Division I and II student-athletes have/will participate in a study abroad program (NCAA, 2016); which is a similar rate to U.S. undergraduate students that study abroad before graduation (IIE, 2018). This is of particular concern, as research has consistently shown positive benefits for students that study abroad, including their returning home with a new perspective on culture and a greater knowledge and understanding of the world (Hadis, 2005). Students also are positively impacted in the areas of intercultural and personal development (Braskamp, Braskamp, \& Merrill, 2009; Dwyer, 2004; Dwyer \& Peters, 2004), academic attainment (Dolby, 2007; Dwyer, 2004; Dwyer \& Peters, 2004; Salisbury, Paulsen, \& Pascarella, 2010), and increased self-confidence (Dwyer \& Peters, 2004; O’Neil, 2017). In response, institutions are making strides to create innovative approaches to increasing student- 
athlete involvement in several HIPs, including providing student-athletes with a global experience through study abroad programs (Ferrari \& Fine, 2016).

As HIPs continue to become an integral part of the college learning process, it is imperative that universities and athletic departments find innovative ways for student-athletes to participate. According to the NCAA (2016), one-third of Division I student-athletes indicated that they would have liked to study abroad but were unable to because of the demands of athletic participation. The following investigation outlines how one university created a unique study abroad experience to allow its student-athlete population to participate. This case study is an example of how such a course, already by definition an academic HIP, was intentionally designed to serve as a vehicle to enhance students' insights into themselves and their team's effectiveness. In what organizational psychologists might refer to as an organization development intervention (Beckhard, 2006; Burke, 2017), this course infused a variety of experiential activities to reinforce course content in practical and meaningful ways. Additionally, this case study describes how the course met Kuh and O'Donnell's (2013) criteria for optional quality HIPs, which include: (a) high academic performance expectations; (b) significant investment of time and effort over an extended period of time; (c) interaction with faculty and peers about substantive matters; (d) exposure to diversity and interaction with people with different life circumstances than their own; (e) frequent, timely, and constructive feedback; (f) structured opportunities to reflect and integrate learning; (g) discovery of relevance of learning through real-world application; and (h) display of competence through public demonstration.

The next section provides a brief background of Elon University, a NCAA Division I program and member of the Colonial Athletic Conference. More specifically, it describes the institution's commitment to HIPs and experiential learning, and specifically, study abroad opportunities for all of its students including student-athletes. Following that contextual overview of the university, the case study will describe the details around the course content and pedagogical methods employed to create a tailored study abroad learning experience for the women's volleyball team - the course labeled GBL 284: Athlete, Team, Nation: Explorations in Culture.

\section{The University's Commitment to Experiential Learning}

Elon University has a strong commitment to engaged learning in the classroom, but also experiential co-curricular learning through what it calls the Elon Experiences (Elon University, 2019b). The Elon Experiences include study abroad, internships, undergraduate research, leadership, and service learning. Students are required to complete a minimum of two of these experiences, the most popular being study abroad. Elon's Isabella Cannon Global Education Center (GEC) has consistently been recognized as the number one master's-level school in students studying abroad with $83 \%$ student participation in study abroad or study U.S.A (Elon University, 2019d).

In Elon University's most recent Strategic Plan called the Elon Commitment, one of the primary themes was "an unprecedented university commitment to diversity and global engagement." A key objective under this theme was to provide $100 \%$ study abroad access (Elon University, 2019a). In an effort to reach this goal, the institution's GEC identified different student populations that had historically low participation rates. One of the populations that was identified 
was student-athletes. To increase access to study abroad experiences for student-athletes, a major initiative was put in place to provide these experiences through participation in a study abroad course which was led by a faculty member for each athletic team cohort. The first of these classes took place in the summer of 2011; following spring semester 2019, all athletic teams will have had the opportunity to study abroad with a plan that every four years each team will study abroad. This is consistent with NCAA legislation that allows student-athletes to participate in foreign tours. This legislation dictates how often, how long, and when these experiences may happen (NCAA Bylaws 17.29.1). In accordance with these rules, Elon typically covers student-athlete costs related to travel, lodging, and planned excursions; it also provides a meal per diem as well as occasional team meals.

Initially there were a number of different models with courses receiving zero to four credit hours for the course, but beginning in the fall 2016 a standardized model was developed and approved by Elon's Global Education Curriculum Committee (GECC). The current version is a two credit hour travel-embedded class that includes a minimum of 15 total hours of classroom instruction: 12 hours before (preparation) and three hours after travel (reflection). The travel usually takes place over nine to 15 days and usually occurs over the institution's week-long spring break or Thanksgiving break in an effort to align with the traditional academic calendar; however, there have been some exceptions when travel has occurred during the summer. In addition to experiencing the new culture and attractions, the student-athletes typically engage in competitions with local teams or clubs during their time abroad.

Destinations over recent years have included Italy, Germany, Japan, Scotland, Costa Rica, the Dominican Republic, and Hawaii (see Elon University, 2019c for a comprehensive list of destinations). From an academic standpoint, courses are designed by permanent Elon faculty members who must submit formal proposals reviewed by the GECC. Course proposals are typically designed in some part around an aspect of the particular professor's academic or other related-knowledge expertise, and considerable flexibility is given to professors in terms of the course content so long as it is relevant to the culture and geographical location. Proposals are first carefully reviewed by the GECC to ensure that they squarely meet the established GECC learning objectives for study abroad experiences; once approved, the proposal is then submitted to and subject to final approval from Elon's university-wide Curriculum Committee.

\section{Summary of Course: Content and Rationale}

The first author and the instructor for the course is an industrial/organizational (I/O) psychologist and full-time member of the university's psychology department. Briefly, I/O psychology is the study of behavior in organizational contexts and includes topics such as job attitudes, personnel management, leadership, teams, organization culture and development. Building on his academic expertise and experience consulting to Fortune 500 organizations, he designed the syllabus with four primary goals: (a) to teach student-athletes about the social phenomenon of culture and its existence and antecedents at multiple levels; (b) to ensure a meaningful experience in Italy, the travel destination, and its culture; (c) to provide tools and activities for them to critically assess their team's culture and overall functioning; and (d) based on these assessments, to facilitate organization development interventions as a means to enhance team functioning. While all of these goals incorporated pedagogy around related key theories, 
terms, and general academic components, the last two were more functional in nature that management scholars and practitioners refer to as organization development. According to Beckhard (2006), "Organization development is an effort (1) planned, (2) organization-wide, and (3) managed from the top, to (4) increase organization effectiveness and health through (5) planned interventions in the organization's 'processes' using behavioral-science knowledge" (p. 3). Although the study abroad component itself was a HIP, the course included a variety of elements and best practices geared to make it a true organization development process aimed at enhancing team members' self-awareness and enhancing their team's functioning.

The examination of culture in the context of athletics and education is not new. As Laker (2002) notes, "[t]here is an inevitable and symbiotic relationship between culture, education, and sport," and that, "[t]his incorporation of sport and education into the meaning of society and culture legitimates them and gives them both a value and a place" (p. 1). Laker (2002) defines culture as, "...a system of shared values, meanings, and symbols that enables societies and individuals to operate effectively without continually redefining these values, meanings, symbols, and points of reference" (p. 2). World-renowned culture scholar Geert Hofstede and his colleagues simplify this and others similar definitions by invoking a systems perspective, defining culture as "...the collective programming of the mind that distinguishes the members of one group or category of people from others" (Hofstede, Hofstede, \& Minkov, 2010, p. 6). How different groups of people hold different shared meanings of objects and phenomena is precisely what makes cultures unique. The importance of culture cannot be overlooked, as it provides us with "a map of how the world works" and "serves to tell us how we fit into the world" (Balzac, 2010, p. 2).

Since how we act is a direct function of our culture, cross-cultural psychology is the formal study of the similarities and differences of behavior in various contexts. Si and Lee (2007) note that only recently has culture been formally included in sports research studies and refer to previous research that findings that, (a) highlighted the important influences that culture has on many factors in sports competition, and (b) made a strong call for the inclusion of culture in future sports psychology research (Duda \& Allison, 1990). Others have begun to recognize the value of including culture as a factor in sports, and not just for competitive teams. For example, Scott (1997) discusses a framework for applying culture as it is typically studied and analyzed to the management of intercollegiate athletics. This case study is an example of a course that was designed to include multiple prescribed elements of high-quality HIPs, and specifically tailored to address Duda and Allison's (1990) call for the deliberate efforts to blend culture, athletics, and education. Going beyond this call, the unique course described in this paper infused activities that not only enhanced student-athlete learning but were designed to enhance their individual and team's effectiveness.

What follows is a summary of the major course activities, topics, and accompanying assignments for the course, Athlete, Team, Nation: Explorations in Culture. The course incorporated experiential activities and HIP elements through the study and application of culture as a multi-level phenomenon. Within the context of a study abroad experience, the course was simultaneously designed to be an organization development intervention for the team. Taken together, students learned about culture at individual, team, and national levels of analyses in a process that led to data-driven interventions to enhance the team's effectiveness. While the descriptions presented below are generally in chronological order, the course's compressed 
timeframe occasionally required that multiple themes be covered during the same course meeting and at other times required topics to be reintroduced. As a means to avoid added confusion and direct focus to the topics covered and their related activities, the following presentation is summarized by major content areas.

\section{GBL 284: Athlete, Team, Nation: Explorations in Culture}

\section{A Model for High Performing Teams}

As a goal was to maximize potential applications of course learning for this group's future competition performance, the 'team' as a unit of analysis received particularly special attention. In contrast to many simple definitions that simply refer to a group of individuals working towards a common goal, Katzenbach and Smith (1993) operationalize high-performance teams as "a small group of people with complementary skills who are committed to a common purpose, performance goals and approach for which they are mutually accountable" (p. 112). Their definition also assumes that team members are deeply concerned and invested in each other's personal growth and development.

As Katzenbach and Smith (1993) clearly state, many if not most teams either ultimately fail to achieve their goals or are suboptimal in their effectiveness or efficiency if they do. Teams permeate all types of organizations throughout society, with hopes that a synergistic effect will result in a greater collective output and performance than the simple sum of individual contributions. Whether they are members of project teams, task-force teams, product development teams, ad hoc teams, sports teams, or any other assembly of individuals working towards a common goal, most individuals can quickly recall in detail a personal experience where serving on a team was disappointing if not an outright awful experience. In many cases, team performance is actually less effective than if individuals simply operated independently. When asked to identify what the root causes were for these unfortunate but frequent failures, people typically refer to "poor teamwork" without providing any further specifics. As Katzenbach and Smith outline, there are multiple facets to be considered in team diagnoses, all of which must meet certain criteria in order to realize the true but often elusive benefits of teams.

The first dimension for highly effective teams that Katzenbach and Smith (1993) identify are clear, specific, and measurable performance goals. Without up-front, clearly defined, and agreed upon goals, the team runs the risk of members moving in different directions, even if they have an achievement mindset. While a potential advantage of teams is the diversity of ideas and experiences they bring, all members must possess what Katzenbach and Smith (1993) refer to as complementary skills. This collection of core skills includes three broad categories: interpersonal (i.e., the social skills and mindset required to communicate and interact in a way that promotes collaboration); problem-solving (i.e., skills that promote innovative thinking such as idea generation, consideration of and building upon others' ideas, and inviting others to challenge one's own); and technical (i.e., having a degree of expertise and knowledge regarding the issue at hand). While a host of other skills can further facilitate team effectiveness (e.g., planning and organizing skills, presentation skills, etc.), complementary skills represent the foundational skills required of highly effective teams. Even if clear and meaningful performance goals are set, attaining them will be difficult if members lack these skills. 
Katzenbach and Smith's (1993) next criterion, common approach, refers to the agreed upon processes and systems by which all team members abide. Norms around establishing goals, managing workflow, and generally managing the group's functioning ensure consistency and efficiency as it goes about its work. Mutual accountability refers to members not only holding themselves accountable for the individual commitments and objectives, but also addressing other members who fail to meet theirs. Providing direct and honest feedback, not to criticize but to guide and help, ensures that performance standards are maintained. Likewise, welcoming and accepting feedback, and not resisting or taking it personally, are aspects of mutual accountability. The final criterion for highly effective teams is members having a deep and genuine interest in each other's continued personal growth and development. It refers to seeing others beyond just a team member, but rather as people who desire to simultaneously attain person goals as well as team objectives. Although these criteria may appear commonsense, the reality is that few teams consciously utilize them as guideposts or assess themselves on them.

\section{Instructor Preparation and Orientation}

Prior to the in-class meetings and departure to Italy, the instructor held a series of meetings with the coaching staff and the thirteen team members to gain a baseline knowledge of the team and its members, norms, goals, and general culture. Such an up-front assessment by a consultant is typical in organization development activities (Burke, 2017). First, the instructor met with the coaching staff and conducted a basic diagnostic interview to learn their perspectives on the team's performance history and overall culture. Additionally, the instructor sought to learn the general strengths and weaknesses based on both performance (e.g., winning percentage, match metrics, etc.) and team functioning (e.g., teamwork, communication, etc.). To establish a level of credibility with the student-athletes later, the instructor asked questions to better educate himself about volleyball in general, including game and strategy basics and current collegiate trends. In addition, he sought feedback on ideas he had for class discussions and activities and explained how each would fit within the goals for the course and the team. These things were done to gain the coaching staff's (or, the "top management" in this context) support, one of Beckhard's (2006) criteria for organization development. The instructor also met with the team captain to conduct a similar informal assessment, which provided additional valuable team information from a different perspective.

Equipped with a foundational knowledge of collegiate volleyball and Elon's team and its players, the instructor then met with student-athletes in groups of two or three over coffee to meet and develop a personal rapport. Organization development requires trust between the consultant (i.e., instructor) and stakeholders (i.e., students). Thus these were informal conversations that focused on individual's background, volleyball history, academic studies, career plans, and similar "get to know you" topics that one would discuss with college students. The instructor shared a brief, high-level overview of the course goals and content, as well as general description of the travel itinerary. Finally, the instructor assigned pre-work that would be covered during the first-class meeting. This initial meeting was very helpful, as it forged an intimate working relationship between instructor and student-athletes. Moreover, explaining how the course and assignments were designed squarely with the purpose of enhancing team performance served as an additional motivator for students, aside from the excitement of traveling to Italy. This course was layered with elements from both cultural and organization developmental 
perspectives. The narrative that follows discusses the major content areas that were covered during the in-class meetings, travel component, and post-course activities. An actual timeline that lists specific activities and during which class period they occurred is presented below (see Table 1).

Table 1

Timeline of Course Activities and Assignments

\begin{tabular}{|c|c|}
\hline Meeting & Session Topics \& Activities \\
\hline Pre-Course Meetings & $\begin{array}{l}\text { - Small group course orientation meetings with players } \\
\text { - } \quad \text { Meetings with coaching staff and team captain to gain insights about team }\end{array}$ \\
\hline $\begin{array}{l}\text { Pre-Departure } \\
\text { Class Meeting } 1\end{array}$ & $\begin{array}{l}\text { - Overview of culture and Schein's (2006) and Hofstede's (2010) models } \\
\text { - Analysis and applications of culture at Elon and other organizations } \\
\text { - Individual insights into personality and identity formation } \\
\quad \text { Jung Typology Assessment, Athletic Identity Measurement Scale, } \\
\text { NEO-PI-3 } \\
\text { - Individual insights into goals and values } \\
\quad \text { Visual Explorer and Values Explorer activities } \\
\text { - Individual insights into cultural perspective and influences } \\
\quad \text { Personal Cultural Identity \& Athletic Identity Worksheet }\end{array}$ \\
\hline $\begin{array}{l}\text { Pre-Departure } \\
\text { Class Meeting } 2\end{array}$ & $\begin{array}{l}\text { - Assessment and discussion of team culture } \\
\quad \text { Volleyball Team Culture Worksheet } \\
\text { - Introduction to national culture and Hofstede's (2010) dimensions } \\
\text { - Discussion and applications of Hofstede's national cultural dimensions } \\
\quad \text { O Volleyball Around the World presentations }\end{array}$ \\
\hline $\begin{array}{l}\text { Pre-Departure } \\
\text { Class Meeting } 3\end{array}$ & $\begin{array}{l}\text { - Overview of travel itinerary } \\
\circ \text { Destination Italy presentations } \\
\text { - Elon native Italian students visit } \\
\circ \text { Italians' perspectives on cultures in Italy and the US } \\
\circ \text { Learning Italian language for travel and volleyball }\end{array}$ \\
\hline $\begin{array}{l}\text { Pre-Departure } \\
\text { Class Meeting } 4\end{array}$ & $\begin{array}{l}\text { - Introduction to team dynamics and Katzenbach \& Smith's (1993) model } \\
\text { - } \quad \text { Rer high performance teams } \\
\text { - Volleyball Team Culture Worksheet } \\
\text { - Teambuilding activity: Marshmallow Challenge } \\
\text { - Analysis and discussion of volleyball team's culture using Katzenbach \& } \\
\text { Smith's model } \\
\text { - Volleyball Team High Performance Worksheet } \\
\text { - Final preparations for travel }\end{array}$ \\
\hline Travel in Italy & $\begin{array}{l}\text { - Various excursions and attractions in Milan, Como, Montecatini, Cinque } \\
\text { Terra, Pisa, Assisi, Florence, Rome } \\
\text { - Class meetings to discuss observations and applications of culture }\end{array}$ \\
\hline
\end{tabular}




\begin{tabular}{|c|c|}
\hline & $\begin{array}{l}\text { - } \text { Competition against } 2 \text { Italian volleyball club teams } \\
\text { - } \quad \text { Clinic hosted for Italian girls at local volleyball club } \\
\text { - Teambuilding activity: Colourblind } \\
\text { - } \quad \text { Reflective journal entries }\end{array}$ \\
\hline $\begin{array}{l}\text { Post Trip } \\
\text { Class Meeting }\end{array}$ & $\begin{array}{l}\text { - Debrief of personal travel experiences and learnings } \\
\text { - Conflict management workshop } \\
\text { - Introduction to Thomas \& Kilmann (2002) Conflict Model } \\
\text { - Individual assessment of conflict management style } \\
\text { - Team assessment of conflict management styles and discussion of } \\
\text { implications } \\
\text { - Feedback workshop }\end{array}$ \\
\hline Post Course Meetings & $\begin{array}{l}\text { - } \text { Goal setting workshop } \\
\text { - } \text { Ongoing consulting with players and coaches }\end{array}$ \\
\hline
\end{tabular}

\section{Introduction to Culture}

Based on Hofstede et al.'s (2010) "mental software" analogy, the first class meeting focused on defining "culture" and how it would be examined at three unique levels, namely, individual, team, and national. Culture is learned through shared understandings and the meanings that group members give to symbols, heroes, rituals, and values. According to Hofstede et al. (2010), symbols are words, pictures, or objects that convey a particular meaning only for members of a particular culture; and heroes are important people, real or imagined, who serve as prototypes and models of behavior for them. Rituals are activities that might not be technically necessary to achieve a goal but are nonetheless essential for social interaction among members. Finally, values are at the core of a culture, and are "...broad tendencies to prefer certain states of affairs over others" (p. 9). Taken together, these elements are learned and adopted by members and serve as the guideposts of how to fit in and provide predictability and stability within a group.

The student-athletes engaged in rich discussions as they first used these lenses to analyze their university's culture. They then diagnosed a variety of other cultures from as broad as the United States to as specific as other athletic teams and even nonstudent-athletes on campus. Included in these discussions were the relative importance and power of different cultures, as well as how they developed and changed. After this topical review of culture, the course moved to studying and applying the finer elements of culture at the individual, team, and national levels.

\section{Culture at the Individual Level}

As the world-renowned organizational culture expert Edgar Schein (2006) mused, when considering one's place in culture a fair question one may ask is: "Am I a unique personality, or just an example of my culture?" (p. 617). In discussing how one understands their own unique culture, both Schein (2006) and Hofstede et al. (2010) posit that one's unique perspective of culture (i.e., how they interpret and bring meaning to things) originates from both hereditary and environmental factors. Their model explains how culture is the intersection between a universal human nature (which is inherited) and an individual's unique personality (which is inherited as 
well as learned). Using an adaptation of Maniam's (2014) model as a framework, students engaged in a number of activities that helped them trace how their own unique perspectives of culture, as well as personal and sports identities were developed, and how these factors ultimately influence their present experience as a member of the volleyball team. In brief, the model begins with identifying the sources of one's ideological and sporting values, which are based on the culture they grew up in and the personality traits they inherited. From there, other factors that further influenced their personal sense of cultural identity (e.g., religion, family, nationality, etc.) and personal sense of athletic identity (e.g., sports selected, reasons for participation, etc.); both of which contribute to their experience as a volleyball team member (e.g., perceptions of success, satisfaction, participation, etc.). Students completed the Personal Cultural Identity \& Athletic Identity Worksheet (see Appendix A), a guided reflective exercise that the instructor created to help them explore these questions. Students also completed a number of additional commercial assessments (described below) to gain further insights as part of this assignment.

Jung Typology Test. Students completed the Jung Typology Test (Humanmetrics, n.d.), an on-line variation of the universally popular Myers-Briggs Type Indicator (MBTI). Like the MBTI, the Jung Typology Indicator provides insights into an individual's preferred style of operating in the world based on four binary dimensions: Introversion (I) versus Extroversion (E), or whether a person is more energized by self-reflection and inner thoughts or by external stimuli including other people; Sensing $(\mathrm{S})$ versus Intuition $(\mathrm{N})$, or whether they are more inclined to focus on empirical and observable information or on broader and more abstract ideas; Thinking (T) versus Feeling $(\mathrm{F})$, or whether their decision-making is guided more by logic and rationality or emotion and gut feel; and Judging $(\mathrm{J})$ versus Perceiving $(\mathrm{P})$, or whether they tend to impose structure and enjoy predictability or operate more spontaneously and be open to new experiences.

NEO-PI-3. Students completed the Neuroticism, Extraversion, Openness Personality Inventory (NEO-PI-3; McCrea \& Costa, 2010), one of the most commonly used tools to assess the Five Factor Model of personality. A refined version of earlier NEO editions, the NEO-PI-3 was specifically designed for college-aged students and demonstrates excellent psychometric properties (McCrae, Costa, \& Martin, 2005). McCrae and Costa (2010) define the five factors in detail; however, in brief, they are: (a) neuroticism (or emotional stability), which reflects a tendency to experience negative effects such as fear, embarrassment, guilt, and sadness; (b) extraversion, which reflects a preference for excitement and stimulation, particularly in social settings; (c) openness, which reflects a general curiosity about one's outer and inner worlds; (d) agreeableness, or the tendency to be sympathetic, trusting, and altruistic; and (e) conscientiousness, or one's general sense of self-control over impulses and achievement orientation. Each dimension is comprised by six facets that offer more specificity into factor scores. A total of 240 Likert-type statements (1=strongly disagree, 5=strongly agree) comprise the NEOPI-3. 
Athletic Identity Measurement Survey (AIMS). Brewer, Van Raalte, and Linder (1993) developed the AIMS to better understand the psychological, emotional, and behavioral aspects of athletes by assessing their athletic identity, or "degree to which an individual athlete identifies with the athlete role" (p. 237). The AIMS is a seven-item Likert-type survey (1=strongly disagree, $7=$ strongly agree $)$ that assesses the latent athletic identity variable through three first order factors: social identity (e.g., "I consider myself an athlete"); exclusivity ("Sport is the most important part of my life"); and negative affectivity ("I feel bad about myself when I do poorly in a sport"). In addition to demonstrating excellent psychometric soundness, Visek, Hurst, Maxwell, and Watson (2008) also found preliminary evidence for the scale's utility in cross-cultural contexts.

Visual Explorer TM Cards. Visual Explorer (Center for Creative Leadership, 2018a) is a projective activity in which an individual selects one of 216, 4 x 6 inch colored picture cards that symbolizes their perception of a given topic. The student-athletes were instructed to select the one that "best represent what the word 'culture' means to you." Individuals were then asked to reflect on and explain their card's meaning, and from where this perception may have originated.

Values Explorer TM Cards. Values Explorer (Center for Creative Leadership, 2018b) is an exercise that prioritizes one's personal values using a deck of 52 cards, each with a value and its accompanying definition (e.g., "justice," "family," "spirituality"). Students were instructed to identify their top ten values; then to reduce those to five, and then two. The visible frustration that many exhibited highlighted the challenge that forced them to prioritize important values over others. The purpose of this exercise was to push students to critically evaluate the degree to which these values were most core to their identities.

\section{Culture at the National Level}

Transitioning from a micro, individual-level analysis of cultural identity, students then turned to a more macro, national-level. Through class discussion and engaging directly with the website, Hofstede-Insights.com, students learned about the six primary cultural dimensions identified by Geert Hofstede (2010), the foremost pioneer in cross-cultural studies. These dimensions are: power distance ("degree to which the less powerful members of a society accept and expect that power is distributed unequally"); individualism versus collectivism ("preference for a loosely-knit social framework in which individuals are expected to take care of only themselves and their immediate families" over "a tightly-knit framework in society in which individuals can expect their relatives or members of a particular ingroup to look after them in exchange for unquestioning loyalty); masculinity versus femininity ("preference in society for achievement, heroism, assertiveness, and material rewards for success" over "cooperation, modesty, caring for the weak and quality of life"); uncertainty avoidance ("degree to which the members of a society feel uncomfortable with uncertainty and ambiguity"); long-term versus short-term orientation ("preference of time-honoured traditions and norms while viewing societal change with suspicion" over "thrift and efforts in modern education as a way to prepare for the future"); and indulgence versus restraint ("relatively free gratification of basic and natural human drives related to enjoying life and having fun" versus suppression of "gratification of needs and regulated by means of strict social norms"). 
Hofstede-Insights.com provides a wealth of information on national cultures, including a "Nation Comparison Tool" function that provides graphic comparisons of countries' dimensional standings. After discussions of the United States' dimensional standards and examples of how they were manifested in everyday life, pairs of students created and delivered Volleyball Around the World presentations where they compared an assigned nation to the United States. To make this activity more relevant and impactful, the nations assigned were those with premier volleyball programs on the world stage: Brazil, China, Dominican Republic, Russia, Serbia, Turkey, and, of course, Italy. In their presentations, students referred to Hostede-Insights.com to give an overview of their nation's standing on Hofstede's dimensions, key facts and figures (e.g., demographics, major cities, key historical events, economies, etc.), and how the experience as a volleyball player might be different from their own as collegians. For the last point, students were encouraged to consider a variety of volleyball-related aspects, such as intra-team communication, relationships with coaches, game strategies, how practices would be run, fans' experiences, and so on. Presentations included information about general organizational structures, recent performance, key players, and key points in history related to volleyball in their nation. As such, students not only learned about cross-cultural dimensions, but did so in a way where they directly applied these learnings to a key and meaningful aspect of their personal and sports identities - the sport of volleyball.

\section{Travel in Italy}

As a means to prepare students for their travel and familiarize them with Italy, pairs of student-athletes prepared brief presentations on an assigned itinerary location; this assignment was referred to as Destination: Italy presentations. Elements included key historical events and people, demographic summaries, major attractions, and many visual images. Done prior to departure, this experience helped make the impending trip come alive and heightened their interest and excitement to travel to these places. Additionally, three fellow undergraduate students who were native Italians were invited to class to share their thoughts and insights about Italian culture. They highlighted some of the major cultural differences and customs between Italy and the U.S., with a particular emphasis on cultural faux pas they should avoid. In addition, they taught the class basic Italian phrases, including those unique to volleyball such as positions, equipment, and compliments. More than simply providing translations, they worked directly with small groups of players and facilitated actual dialogue and coached pronunciation. This session was extremely valuable and engaging for the players, and more deeply informed them of true Italian culture.

All travel logistics were coordinated by a travel partner that specialized in managing athletic team tours. Travel occurred over spring break, so no academic classes were was missed. After landing in and visiting Milan, the group travelled a southernly route that included Como, Montecatini, Cinque Terra, Florence, Pisa, Assisi, Vatican City, and Rome. In addition to scheduled group activities, students were given time to explore and immerse themselves in the cultures on their own, during which they sampled Italian food, cafés, shops, and general aspects of daily life and culture. Among the group's experiential activities were guided city, cathedral, vineyard, and museum tours, as well as hands-on activities such as taking an Italian cooking class and participating in an Italian wine-tasting demonstration. The team also had the opportunity to compete in two matches against Italian club volleyball teams, which was a real-time demonstration of how a unique shared culture (i.e., that among competitive volleyball players) in many ways 
transcended national cultures. In this context, the players directly observed how they had a similar appreciation for the values, rituals, and symbols unique to volleyball with other people whose spoken language they did not know. Such learnings were even more visible when the players hosted a volleyball clinic for pre-teens girls at a local club. Whereas many of the Italians with whom the players interacted during the trip spoke English, these young girls did not. Nonetheless, after some initial nervousness and confusion, the Elon players quickly adapted to create a shared culture with their students through physical demonstrations and motions, cheering and clapping, and facial expressions. Again, the power of the shared meaning of volleyball rituals (e.g., warm ups, position responsibilities), symbols (e.g., ball, referee, court lines), and values (e.g., competitiveness, athleticism, teamwork) very quickly resulted in two previously independent groups participating in complex drills together, giving and sharing knowledge in their own volleyball language, and developing close personal bonds through excited high-fiving and hugging each other. A highlight of the trip for many players was seeing observers in the crowd clapping and chanting, "Elon! Elon!" in appreciation of the players' goodwill during their clinic. This, and the overall experience, were tremendous for the players to see the evolution of culture in the context of their personal and athletic identities.

While in Italy, periodic "in-class meetings" took place in gelato shops and hotel sitting rooms as a means to still be in Italian culture. In addition to facilitating discussions around players' reflections of their daily experiences, the instructor challenged students to interpret Italians' behaviors and customs and discuss how they would be perceived in the United States.

As a means to maximize their personal experiences through guided reflection, students kept journals to chronicle their experiences. In order to introduce them to different methods, students were taught an alternative method to keep a journal as outlined in Paige, Cohen, Kappler, Chi, and Lassegard's (2010) popular book, Maximizing Study Abroad. Noting that most people focus so heavily on capturing daily details, Paige et al. suggest dividing a journal into four different sections. The first is an impressions section, which is much like a chronological account where notes are made purely to spark memory later on. The focus is on the specific people, events, places, and any other observations that are recalled, and in the form of personalized shorthand of sorts rather than formal prose. The descriptive section involves writings that create a vivid picture of what was experienced in a way that someone else reading it could create a mental picture from the written words. Paige et al. (2010) note that chapter titles here might include "People," "Customs," "Places," or some other broad category of experience, with content that is more objective and purely descriptive in nature. The narrative section is where one can record particularly interesting personal anecdotes. Finally, the expressive section is more evaluative in nature, and allows for the writer to express their personal emotions, reactions, and general feelings about something they observed. Whereas the previous sections offer outlets for chronologizing and describing events for future reference or recall, this section is where deeper thinking and reflection on experiences result in greater personal learning.

Each player was also tasked with creating a videotaped summary, or vlog, to highlight the team's activities for an assigned day. After consultation and editing activities were completed with a member of the athletics media department who was also travelling with the team, these vlogs were posted daily (see https://elonphoenix.com/news/2018/3/20/womens-volleyball-elon- 
volleyball-in-italy-vlog-no-1.aspx) to the Elon Athletics Department's webpage so that the broader campus community could follow the group.

\section{Culture at the Team Level}

As Schein (2006) noted, culture assessment is critical when any organization of people seek ways to become more effective. According to Levi (2014), team culture is "...the shared perception of how the team should operate to accomplish its goals" (p. 264). It refers to the agreed upon norms and behavioral expectations that bind members together, which are usually a function of broader organizational and societal cultures. As it is in any organization, team culture is considered successful if it is in harmony with and able to function in its environment (Balzac, 2010). The players individually completed the Volleyball Team Culture Worksheet (see Appendix B), another diagnostic exercise that the instructor created that asked the players to describe their team on a host of culture-related activities and issues such as how new members were integrated, how the prototypical Elon volleyball player behaved, what sacred but unspoken rules were followed, whether subcultures existed, and a variety of more specific questions about team values, symbols rituals, and heroes. The instructor summarized and presented themes to the group, which prompted discussion around the relative importance of selected elements and whether any should be modified. For an additional in-depth assessment of the team and its functioning, the instructor created team summary profiles based on the MBTI, NEOPI-3, and AIMS by aggregating individuals' scores. Dimensions and factors that were relatively higher or lower or exhibited considerable variability were discussed in detail, particular in terms of how they possibly impacted team dynamics and performance. Taken together, these summaries enabled rich discussion of team members' perceptions, many of which came as surprises to others.

Teambuilding Activities. To gain further insights into the team's dynamics, the instructor facilitated two well-known activities frequently used in organizational and team consulting contexts. Colourblind (RSVP Design, 2018) is a team activity in which members work together to solve a challenging puzzle while blindfolded. The simulation brings to light the importance of communication and group processes and norms to team problem-solving, as well as how to overcome obstacles and manage conflict that naturally arises. As is typical for this simulation, in this microcosm the group was observed going through Tuckman's (1965) classic phases of team evolution: forming, storming, norming, and performing. Unsure of how to begin this complex and unfamiliar task, participants spent the first few minutes lightly discussing the parameters and instructions and generally got oriented to the task and how they would work together (forming). Initial efforts to manage the task were involved in multiple ideas being communicated with different factions following different procedures, the formation of subgroups, miscommunication and poor coordination, and ultimately, frustration and arguments (storming). Eventually, more focused conversations ensued where lessons from earlier attempts were discussed and differences resolved to develop a more unified approach (norming). Finally, with everyone operating within agreed-upon guidelines (and in essence, a new culture specific to this new task), the team began making faster progress towards its goal (performing). The team ultimately completed it in only 20 minutes which is relatively fast compared to (a) the typical 35-40 minute timeframe that the instructor has observed over dozens of previous administrations with other teams, and (b) the publisher's suggested timeframe of 15-60 minutes. 
The team also participated in the Marshmallow Challenge, (Wujec, 2010) a popular team activity in which groups of three are challenged to build a free-standing structure in eighteen minutes, using twenty pieces of spaghetti, one yard of masking tape, one yard of yarn, and one marshmallow that must sit atop the structure. This activity has been widely used among groups ranging from kindergarteners to business executives and serves as an excellent intervention to highlight group processes including creative problem-solving, communication, planning, and execution. Also fun in nature, the activity similarly offers a wealth of insights into a group's processing. It also breeds a sense of competitiveness among teams, which added a further insight into the team's approach to accomplishing goals.

After each activity, the instructor facilitated a debrief that focused on players' general reactions to the challenges, what worked and didn't work, and how they would approach the task again in the future. In addition, players were asked to relate their experiences to the team's culture and overall functioning and team processes. For example, players discussed how Colourblind represents the evolution of the team over a season, where the challenges involving getting used to new players and systems dissipate to a point where everyone converges on a common approach and mindset; only at that point is optimal performance achieved. Players discussed the importance of communication (e.g., how the tone of one's voice and other nonverbals when giving constructive feedback during a heated match can be interpreted differently and have differential impacts on various players), conflict management (e.g., how letting personal disagreements among teammembers fester often causes more discomfort than simply discussing the issue up front), and problem solving (e.g., how the team went about making adjustments to an opponent's change in strategy during a match) in these activities, and highlighted how these dynamics fit directly into the context of the volleyball's culture and team effectiveness. While the players initially saw these activities as "fun" and as an opportunity to temporarily break away from "regular" course content, they quickly realized the connection between the activities and their experiences as an Elon volleyball player. Initial laughter and anecdotes from the task transformed into serious discussions about how these observations could be used to strengthen the team. In other words, these activities were experiential and contained elements of HIPs that fostered active engagement and effected important learnings that were directly applicable to the team and its future success.

Team Analyses. While the aforementioned aggregation of individual assessment results provided a good platform to discuss the team's general characteristics in personality terms, these profiles were nonetheless based on the individual student-athlete as the unit of analysis. As a team, effectiveness and culture are not simply the function of an additive process; the student-athletes were introduced to a format for assessing the team as a whole. Students were introduced to Katzenbach and Smith's (1993) Model for Highly Performing Teams and used it as a framework to assess their team's effectiveness. The authors' model is based on their extensive consulting experience for the prestigious McKinsey Consulting international firm, and their ideas are widely read and adopted by academicians and practitioners alike. Students also read selected passages from Levi's (2014) book Group Dynamics for Teams to gain a foundational understanding of member cohesion, roles and norms, and other fundamental team dynamics. Students also individually completed the third diagnostic that the instructor created, the Volleyball Team High Performance Worksheet (see Appendix C). This assignment was an in-depth assessment which included specific questions about each of Katzenbach and Smith's model for high-performing teams. An extensive inventory, it asked each player to (a) assess all team members on their 
complementary skills; (b) articulate their understanding of the team's specific performance as well as what they thought they should be; (c) describe and assess the team's common approaches on a host of activities (i.e., managing conflict, managing communication, running practices, etc.); (d) describe and assess how team members held each other accountable (i.e., providing and accepting feedback); and (e) describe the extent to which team members cared about each other's development.

The instructor again summarized the results to share with the team with a particular focus on the themes that teammembers most frequently identified. In terms of complementary skills, teammembers identified the relative strengths and weaknesses at each position: they identified working collaboratively and communicating volleyball-related information as the team's overall greatest strengths and addressing interpersonal conflict and adapting to certain opponents' changes in game plans as relative weaknesses. Some of the major goals included maintaining the team's reputation for being serious academic students and highly engaged in nonathletic-related campus activities, winning the first match in the team's newly constructed venue, beating a particular archrival opponent, and attaining certain win-loss records for the season. In terms of a common approach, some themes identified were that teammembers were very supportive of each other and "always had each other's back," ran efficient team meetings, and were very good about keeping each other informed. Also, they were more prone to avoiding conflict than addressing it because they wanted to preserve harmony and relationships, and that there was opportunity to improve how they responded to certain game situations. The main theme around mutual accountability was that players were more likely to hold themselves accountable than others and that there was some hesitation to provide negative feedback or directly confront someone when they were violating team norms or performing. At the same time, teammembers expressed a sincere desire to see each other grow as an athlete and person and wanted to help them in the process. The particular constellation of placing high value on supportive and harmonious relationships and having a genuine desire to help and support each other, while at the same time hesitating to provide feedback or engage in healthy disagreements, became the major focal point for discussion and how these things impacted the team and, more importantly, what it meant for the team going forward.

Prior to sharing the results, the professor established discussion ground rules that included having an open mind, maintaining respect for everyone, ensuring that everyone felt comfortable expressing their ideas, encouraging everyone's participation, and that all discussion ultimately had the simple aim of bettering the team in terms of performance, process, or both. The discussion that followed these summaries was rich as it provided a wealth of specific information on a variety of factors that had not previously been discussed. The players' assessments of each other's complementary skills were summarized (anonymity was maintained) by the instructor and in a confidential individual report. Utilizing data and other social science practices to diagnose a team in order to identify the most appropriate interventions is a hallmark of organization development; basing a planned and managed change on that that data is another (Beckhard, 2006). From the facilitated discussions as well as his own analysis and insights including those gleaned from observations during travel in Italy, the instructor presented to the team what team dynamics he thought were most ripe for intervention. After more discussion and gaining the team's buy-in to his suggestions, the instructor met with the coaching staff to inform them of the proposals as a means to gain their support. Such approval from "top management" is also an essential element of organization development (Beckhard, 2006). 


\section{Team Interventions}

The organization development interventions that were selected were managing conflict and delivering feedback. To note, identification of these areas was not solely based on the lowest dimensional ratings, but rather on the extent to which they would have the greatest positive impact. The instructor then developed and delivered two workshops to address these areas, one of conflict management and another on delivering feedback.

Conflict Management. The instructor created a 60-minute workshop on conflict management. First, the student-athletes individually completed the Thomas-Kilmann Conflict Inventory (TKI; Thomas \& Kilmann, 2002) to assess how they were likely to address conflict. The TKI is the most widely used instrument to assess conflict styles and is comprised of 30 forcedchoice items (each with two alternatives) that assesses an individual's standing on two core dimensions: assertiveness (i.e., the extent to which they focus on satisfying their own personal concerns) and cooperativeness (i.e., the extent to which they focus on satisfying the other person's concerns; Thomas \& Kilmann, 2002). The result is five conflict management strategies. The first is competing, or when the focus on self is high and focus on others is low, and is typified by a more aggressive, dominant style. The opposite is accommodating, where the focus on others is much higher than on one's self and is typified by acquiescing and giving in as a means to preserve the relationship. Avoiding is the strategy when the foci on both others and self is low and conflict is essentially ignored altogether; opposite to that is collaborating, which occurs when there is a strong desire to serve both one's own and the other's needs and is represented by give and take as a means to resolve the conflict with a mutually satisfying solution. Finally, compromising is a middle-of-the-road approach where there is a balanced focus on one's own and another's needs and involves give-and-take exchanges.

Players were provided with individual feedback and asked to reflect on their own preferred styles. Discussion ensued around the nature and cause of the conflicts that typically arose within the team and what each strategy might look like when addressing it. The likely potential impacts of each style were also explored, as was the reality that any of them might be the most appropriate for a given situation. In other words, the student-athletes were encouraged to see all styles as offering choices as to how to approach a specific conflict with a particular individual.

From there, the instructor shared a composite that showed (anonymously) where all teammates' strategies fell relative to each other. As would be expected in any group of thirteen, there was a variety of styles. However, there was a relatively higher percentage of players in the accommodating and competing strategies, with fewer in the avoiding or compromising. In other words, the team was represented by one group whose primary strategy was to be dominant and another group whose strategy was to go along with what others wanted. As a result, conflict issues tended to be one-sided without reciprocal dialogue and give-and-take; in turn, this resulted in some players being perceived as too aggressive and others being more passive aggressive. The studentathletes discussed issues where this dynamic had indeed occurred in the past, then talked about how such conflict discussions would be improved both in terms of team process as well as in quality of decisions. For some of the competing types, this discussion was eye-opening in that they had simply assumed that others who didn't speak up were in essence giving them their approval. 
Likewise, for those accommodators, hearing these stories helped them see that competing types weren't always looking to dominate them and would be more receptive to ideas if they were actually shared. Finally, the necessity of healthy conflict for high performing teams was impressed as, if managed well, it can lead to more thoughtful discussions and optimal solutions. In summary, this workshop helped the players see how conflict was a more complex phenomenon than they had realized and that approaches to manage it could be modified as a means to help the team achieve its performance goals while also preserving positive interpersonal relationships and processes.

Delivering Feedback. The instructor also created a workshop that focused on best practices in giving meaningful feedback. It began with an overview of the benefits of feedback, why it is so hard to give, why it is hard to receive, and the negative impact (both on interpersonal relationships and performance) that it can have when delivered poorly. A philosophy of feedback was shared, in which it is ideally viewed as positive and constructive, and ultimately requires trust between the feedback giver and receiver in order for it to have optimal effects. The team was reminded of earlier assessment results that indicated that there was generally a high level of trust among team members, as well as overlooked good interpersonal relationships and cohesion. As these core foundations for meaningful feedback had already been established, what was needed was a formula to give feedback in a way that didn't make them or others feel uncomfortable (i.e., either being too direct and pushy, or too hesitant and not direct enough). Students were taught a new technique to provide feedback, in what the instructor described as being more "whole" and "complete" way. The first of four elements in a whole message is observation, or event that is factual and or can be empirically demonstrated. The second is thought, which is the giver's cognitive reaction or opinion of the observation (i.e., "I think..." or "I believe ..."); and the third is feeling, which is the giver's emotional reaction (i.e., "I feel..." or "I worry...") to the same observation. The final element is the next step, or what proposed solution or idea for going forward is offered. Players were taught that each component should be included for any message to be fully understood, as well as share the giver's reactions to it. For example, if a teammate was concerned about a fellow teammate's level of effort in a previous game, typical feedback, if any, might be, "Why were you down last game?" or "I think you need to play with more intensity." Both examples, and others, include valid information but are missing others that will make it less likely that the recipient accepts it without defensiveness or complete understanding. For example, a message such as, "Susan, last night you had five service errors. I think that might be because you were tired and not getting enough sleep. I worry that if you don't develop better ways to manage your time, both you and the team won't be as competitive as we need to be. Is there a way that maybe you could talk to Jennifer about how she goes about scheduling her days, because she is really efficient?"

Students were further taught that these components could be fine-tuned to a given situation and might perhaps be communicated throughout a conversation rather than all at once. The instructor shared additional best practices for creating whole messages, including brainstorming ideas first and then selecting the most appropriate elements to craft a clean, integrated, and impactful message. After generating some whole messages as a group to hypothetical, yet realistic scenarios that they might encounter in the context of the volleyball team (e.g., situations involving someone playing extremely well, someone not meeting expectations, someone treating someone else harshly, someone struggling to adapt, etc.), each player was assigned another teammate to whom they had to write whole messages. The players wrote them out and then shared them with 
their assigned team members. This process minimized defensiveness since they were all doing it as a group and forced them to apply whole message feedback to a real volleyball context. Like the workshop on conflict management, this offering exemplified Beckhard's (2006) conditions of organization development.

\section{Discussion}

Overall, the course received outstanding feedback from the student-athletes and was considered an overall success on multiple dimensions. By tailoring the course content to make it relevant to the student-athletes and infusing multiple experiential elements, most of Kuh and O'Donnell's (2013) criteria for high-quality HIPs were convincingly met. While the following is not an exhaustive list, it highlights some selected examples of activities and outcomes related to the characteristics. First and foremost, academic rigor and high performance expectations were evident through students' item ratings on the university's standard course evaluation form. Specifically, items such as, "The instructor set a high standard for achievement that students were encouraged to meet" (5.67/6.00) and "The instructor expected students to support assertions with evidence and/or reasoning" (6.00) reflect the level of academic rigor and challenge. These ratings are a function of the second criterion related to students' investment of time and effort. Although a short-term course, students invested a substantial amount of time outside of class reading, completing written assignments, and preparing presentations: the item mean for, "I have consistently put a lot of effort into meeting course objectives" was 5.63. Also, their trip to Italy was a highly active and engaging one with excursions filling their daily itineraries on top of occasional class meetings during the evenings.

Kuh and O'Donnell's (2013) next criterion, that of frequent and meaningful interactions with faculty and peers, was addressed on multiple levels. First, as the instructor essentially simultaneously served as a team consultant as much as a teacher, numerous discussions on important personal and team-related issues were had. Close and trusting relationships were formed between instructor and students, which facilitated sometimes difficult but necessary dialogue around the team's culture and functioning; the coaches were also invited to some of these discussions and share their perspectives. Travelling over a period of time also afforded the instructor to get to know each player on a personal level that allowed for private conversations about personal goals and identities and how they fit with team dynamics and functioning. The criterion of having exposure to different cultures and diversity was met prior (e.g., presentations on volleyball-playing countries, presentations on itinerary sites, Italian student peers teaching about Italian culture and language) and obviously during the time in Italy. The more intimate settings (e.g., attending the Italian cooking class and wine tasting), and perhaps most so, the clinic the students hosted for the young Italian girls; were the most transformative of these experiences. Here, they experienced first-hand the power of volleyball culture as it transcended spoken language as keys to building relationships and working with others.

The instructor provided ongoing guidance and feedback, Kuh and O'Donnell's (2013) next criterion, not only on assignments but perhaps more importantly on the team's discussions and analyses of the team's functioning and other sensitive issues. A key to any organization development intervention is having a consultant support and guide a team or organization through its learning and development. The items, "The instructor gave me feedback that helped me learn," 
"The instructor facilitated my learning of the subject material," and "The instructor supported a class environment of mutual respect," all received perfect ratings from all students, further evidence of the of the meaningfulness of these interactions. Students were also expected to reinforce and integrate their learnings through personal reflection, the next criterion. The various assessments and worksheets they completed to critically analyze themselves and their team all required deep guided reflection and application. While in Italy, evening debriefs on the observations and learnings of that day and formal journal entries further promoted deeper and more focused reflection. Journal entries provided further support, as they offered glimpses into students' direct experiences with Italian culture and people. Overall, the journal entries consistently reflected a transformative experience with references to personal insights, explanations, and commentaries on this immersive experience. The mean rating for the item, "The instructor challenged students to think critically about course material" was 6.00 , providing evidence for their commitment to active reflection.

Public demonstration of competence, another of Kuh and O'Donnell's (2013) criteria, was a bit more difficult to assess. Nonetheless, the students delivered multiple presentations, created a vlog to be posted on the university's website, and engaged in conversational Italian. However, perhaps the criterion that was most squarely addressed was having opportunities to discover the relevance of learnings through real-world applications. While there were other examples of this, the organization development-like approach in which elements of culture were studied and directly applied to the individual players and their team is the most sweeping. Beyond learning how to analyze culture at the individual, team, and national levels, the students incorporated this knowledge into models of teamwork and interpersonal dynamics to enhance their team's effectiveness. Moreover, these learnings and applications extend beyond simply a team context; rather, culture and team assessment, delivering feedback, managing conflict, and a host of other topics and skills are transferable to organizations they will work with throughout their lives.

The course itself was designed to be an organization development initiative in accordance with best practices and criteria (Beckhard, 2006). Based on multiple sources of student-generated data, planned interventions (i.e., workshops) were implemented with the ongoing full support of management, or in this case, coaching staff. Because the instructor had come to know the team members and coaches so intimately through these experiences, the coaching staff invited him to continue working with the team after the course had formally ended. So many observations and insights into the individual student-athletes and their team's culture and dynamics provided the instructor with a wealth of information to work from. In essence, the instructor became a "organizational consultant" of sorts to the team similar to as if he was working with an actual organizational client. For example, the team captains frequently sought to meet with him to discuss various team issues. During the meetings, the instructor would engage in process consultation activities, such as asking questions to help the captains reframe issues, consider potential impacts on relevant stakeholders, and think about issues from multiple perspectives as they considered alternative actions.

The instructor also offered to facilitate a goal-setting workshop similar to how he would do so with actual clients. Referring back to the data that students generated during the course, he taught them and coaches best practices for establishing SMART goals (i.e., goals that are specific, measurable, achievable, relevant, and time bound) and facilitated discussions that led to the 
identification of the most relevant goals that included both team performance and process goals. Although this occurred after the completion of the course, the workshop was another meaningful and transformative experience that captured many of the above elements that the AAC\&U and LEAP prescribe for optimal HIPs.

\section{Limitations and Implications}

As with any academic course or organization development intervention, this experience was not without limitations and opportunities for improvement. From a methodological standpoint, more intentional and rigorous data collection methods could be employed during the class activities and discussions. Analyses and conclusions were generally made by the instructor on the basis of his rational and clinical judgement, as well as his experience in facilitating such discussions. From that standpoint, the conclusions found here can be considered valid; however, more precise collection and analysis of data would establish much more scientific credibility. Also, as the team here is directly identifiable, a certain discretion was employed in the level of detail that could be shared without divulging too much that would violate its privacy. A study designed to preserve greater anonymity might allow for more complete sharing of results. This brings to point the issue that this course was designed to allow potential issues ripe for eventual intervention to arise through the process; in other words, at the start of the course, the instructor had no preconceived notions about the team's dynamics or functioning or that developments in the course would lead to the workshops that it did. A different approach would be to conduct some form of pre-test before the course on general team effectiveness and then a subsequent post-test. This would allow for a better testing of whether the course itself and follow-up interventions indeed had direct impacts. Alternatively, one could do an upfront assessment, identify from it a specific element of teamwork (e.g., conflict management) in need of improvement, and then design a course that could specifically address it. The effectiveness of such a targeted approach could be better assessed; however, addressing such a specific topic in a course might be more challenging to directly link to the course content related to the location of a study abroad experience. That said, with some ingenuity, one might be able to center on a topic like conflict management by complementing its application to teams with examination of historical and current divisive issues in the nation and how leaders and other individuals worked to resolve it. Regardless, educators should continue to explore possibilities in which student-athletes not only have the chance to study abroad, but also acquire academic knowledge through credit-bearing courses that can still be directly applied to their individual and/or team's functioning.

The study abroad component aside, this course highlights the benefits that organization development techniques can bring to collegiate athletic teams, and this in turn offers a vista of potential applications. Just as business leaders rely on such interventions to enhance their organization's effectiveness, coaches and administrators could engage in similar activities to not only increase their teams' performance, but also teach their student-athletes concepts and tools that they can use in their post-graduate lives. For example, if a coach were able to gain deeper insight into their student-athletes' motivations and natural conflict management styles, they might be in a better position to tailor their feedback in a more personalized, meaningful, and effective way. Or, if a team were suffering from a particular issue, for example a lack of cohesion and trust among teammembers, a coach might benefit from bringing in a consultant to facilitate a session with them to surface the issue to teach new skills to address it. Many organizations rely on consultants to 
conduct periodic pulse checks on teams as a means of monitoring the well-functioning of its dynamics. Coaches could similarly invite someone to facilitate dialogues or administer surveys on an ongoing basis as a menas to to assess their team's effectiveness. Not only would this promote better team functioning, but it would also teach student-athletes the importance of ongoing assessment. Of course, if one is to conduct assessments and explore potential organization development interventions, they should have expertise in the content area and be qualified in facilitation and measurement. Coaches, who are not all likely to have such expertise and experience, could employ an external consultant; alternatively, a less expensive option would be to inquire whether their school's business (particularly management and organizational behavior) and social science (psychology and sociology) departments have faculty who would do this.

Admittedly, this case study was comprised of many interrelated parts, some of which (i.e., output from activities and discussions, and design of the workshops) could stand on their own as a single study. It was in many ways an evolution that began with the identification of a meaningful and thematic topic around which the instructor could create a short-term study abroad course. Moreover, the goal was to select a topic that would also be relevant in the present and future to student-athletes and their team. Culture was the chosen topic, as it applies to national (i.e., Italy), team (i.e., collection of volleyball players), and individual (i.e., individual players) levels and was studied at each. More critical focus was on the team as the primary unit of analysis, so it was more thoroughly assessed and discussed. The resultant workshops were purely a function of these activities and presented as interventions designed to enhance team effectiveness and culture. As such, although all elements of the course are sequentially related, the course as a whole was an organic experience rather than a prescriptive one at the onset, just as effective organization development in the professional sector typically are.

This case study is one example of how best practices for creating and teaching a study abroad course can provide student-athletes with a unique and personally meaningful learning experience. As colleges and universities continue to strive to provide all of their students with HIPs opportunities, they as a collective body will come closer to answering the Boyer Commission's (1998) original call for a "new model of educating at undergraduate research universities" and support the ongoing initiative by the AAC\&U's LEAP. It is at this point that they will provide the educational opportunities student-athletes truly deserve. 


\section{References}

Balzac, S. (2010). The McGraw-Hill 36-hour course: Organizational development. New York, NY: McGraw Hill.

Bauer, K.W., \& Bennett, J.S. (2008). Evaluation of the undergraduate research program at The University of Delaware: A multifaceted design. In R. Taraban \& R. L. Blanton (Eds.), Creating effective undergraduate research programs in science: The transformation from student to scientist (pp. 81-111). New York, NY: Teachers College Press.

Beckhard, R. (2006). What is organization development? In J.V. Gallos (Ed.) Organization development: A Jossey-Bass reader (pp. 3-12). San Francisco, CA: Jossey-Bass.

Boyer Commission on Educating Undergraduates in the Research University (1998). Reinventing undergraduate education: A blueprint for America's research universities. Stony Brook, NY: State University of New York. Retrieved from https://files.eric.ed.gov/fulltext/ED424840.pdf

Braskamp, L.A., Braskamp, D., \& Merrill, K. (2009). Assessing progress in global learning and development of students with education abroad experiences. Frontiers: The Interdisciplinary Journal of Study Abroad, 18, 101-111.

Brewer, B.W., Van Raalte, J.L., \& Linder, D.E. (1993). Athletic identity: Hercules' muscles or Achilles' heel? International Journal of Sport Psychology, 24, 237-254.

Burke, W. (2017). Organizational change: Theory and practice ( $5^{\text {th }}$ edition). Thousand Oaks, CA: Sage.

Center for Creative Leadership. (2018a). Values Explorer ${ }^{\mathrm{TM}}$. Greensboro, NC: Center for Creative Leadership.

Center for Creative Leadership. (2018b). Visual Explorer ${ }^{\mathrm{TM}}$. Greensboro, NC: Center for Creative Leadership.

Cole, D., \& Espinoza, A. (2008). Examining the academic success of Latino students in science technology engineering and mathematics (STEM) majors. Journal of College Student Development, 49(4), 285-300.

Dolby, N. (2007). Reflections on nation: American undergraduates and education abroad. Journal of Studies in International Education, 11(2), 141-156.

Duda, J.L., \& Allison, M. (1990). Cross-cultural analysis in exercise and sport psychology: Avoid in the field. Journal of Exercise \& Sport Psychology, 12, 114-131.

Dwyer, M.M. (2004). More is better: The impact of study abroad program duration. Frontiers: The Interdisciplinary Journal of Study Abroad, 10, 151-163. 
Dwyer, M.M., \& Peters, C.K. (2004). The benefits of study abroad. Transitions Abroad, 37(5), $56-58$.

Elon University (2019a). The Elon Commitment. Retrieved from https://www.elon.edu/e/administration/president/strategic-plan-2020/

Elon University (2019b). Experiential learning. Retrieved from https://www.elon.edu/u/academics/global-education-center/

Elon University (2019c). Elon Phoenix: Global experiences. Retrieved from https://elonphoenix.com/sports/2016/2/12/ATH_0212164806.aspx?path=general

Elon University (2019d). Isabella Cannon Global Education Center. Retrieved from https://www.elon.edu/u/academics/global-education-center/

Ferrari, C.M., \& Fine, J.B. (2016). Developing global perspective in short-term study abroad: High impact learning through curriculum, co-curriculum and community. Journal of Global Initiatives: Policy, Pedagogy, Perspective, 10, 109-122.

Gayles, J.G. (2009). The student-athlete experience. New Directions for Institutional Research, $144,33-41$.

Hadis, B.F. (2005). Why are they better students when they come back? Determinants of academic focusing gains in the study abroad experience. Frontiers: The Interdisciplinary Journal of Study Abroad, 11, 57-70.

Hofstede, G., Hofstede, G.G., \& Minkov, M. (2010). Cultures and organizations: Software of the mind ( $3^{\text {rd }}$ ed.). New York, NY: McGraw Hill.

Humanmetrics (n.d.). Jung Typology Test. Retrieved January from www.humanmetrics.com/cgiwin/jtypes 2 .asp

IIE (2018). Research and insight: Open doors data. Retrieved from https://www.iie.org/Research-and-Insights/Open-Doors/Data

Katzenbach, J.R., \& Smith, D.K. (1993). The wisdom of teams: Creating the high-performance organization. Cambridge, MA: Harvard Business Publishing.

Kilgo, C.A., Ezell-Sheets, J.K., \& Pascarella, E.T. (2015). The link between high-impact practices and student learning: Some longitudinal evidence. Higher Education, 69(4), 509-525.

Kuh, G.D. (2008). High-impact educational practices: What they are, who has access to them, and why they matter. Washington, D.C.: Association of American Colleges and Universities. 
Kuh, G.D., \& O’Donnell, K. (2013). Ensuring quality and taking high-impact practices to scale. Washington, D.C.: Association of American Colleges and Universities.

Laker, A. (2002). Culture, education, and sport. In A. Laker (Ed.), The sociology of sport and physical education, (pp. 1-13). New York, NY: Routledge Farmer.

Levi, D. (2014). Group dynamics for teams (4 ${ }^{\text {th }}$ ed.). Los Angeles, CA: Sage Publications.

Linn, M.C., Palmer, E., Baranger, A., Gerard, E., \& Stone, E. (2015). Undergraduate research experiences: Impacts and opportunities. Science, 347(6222), 627.

Maniam, V. (2014). Sports participation and cultural identity in the experience of young people. Bern, Switzerland: Peter Lang AG.

McCrae, R.R., \& Costa, P.T. (2010) NEO inventories for the NEO Personality Inventory-3 (NEO-PI-3), NEO Five-Factor Inventory-3 (NEO-FFI-3), NEO Personality InventoryRevised (NEO PI-R): Professional manual. Lutz, FL:PAR.

McCrae, R.R., Costa, P.T., \&, Martin, T.A. (2005). The NEO-PI-3: A more readable revised NEO Personality Inventory. Journal of Personality Assessment, 84, 261-270.

Nagda, B.A., Gregerman, S., Jonides, J., von Hippel, W., \& Lerner, J. (1998). Undergraduate student-faculty research partnerships affect student retention. The Review of Higher Education, 22, 55-72.

National Survey of Student Engagement (2017). National Survey of Student Data: NSSE 2017 High-Impact Practices. Retrieved from http://nsse.indiana.edu/2017_Institutional_Report/pdf/NSSE17\%20HighImpact\%20Practices\%20(NSSEville\%20State).pdf

NCAA. (2016). Results from the 2015 GOALS Study of the Student-Athlete Experience. The 2016 NCAA Annual Convention. Retrieved from https:/www.ncaa.org/sites/default/files/ GOALS_convention_slidebank_jan2016_public.pdf

O’Neil, C. L. (2017). Study abroad and student-athlete choice (Order No. 10754108). Available from ProQuest Dissertations \& Theses A\&I. (2007302076). Retrieved from https://ezproxy.elon.edu/login?url=https://search.proquest.com.ezproxy.elon.edu/docview /2007302076? accountid=10730

Paige, R.M., Cohen, A.D., Kappler, B., Chi, J.C., \& Lassegard, J.P. (2010). Maximizing study abroad: A student's guide to strategies for language and culture learning and use. Minneapolis, MN: University of Minnesota.

Pascarella, E.T., \& Blaich, C. (2013). Lessons from the Wabash National Study of Liberal Arts Education Change: The Magazine of Higher Learning, 45(2), 6-15. 
Potuto, J., \& O'Hanlon, J. (2007). National study of student-athletes regarding their experiences as college students. College Student Journal, 41(4), 947-966.

RSVP Design (2018). Coulourblind $®$ team building and communication training game. Paisley, UK: RSVP Design.

Salisbury, M.H., Paulsen, M.B., \& Pascarella, E.T. (2010). To see the world or stay at home: Applying an integrated student choice model to explore the gender gap in the intent to study abroad. Research in Higher Education, 51, 615-640.

Schein, E.H. (2006). So how can you assess your corporate culture? In J.V. Gallos (Ed.), Organization development (pp. 614-633). San Francisco, CA: Jossey Bass.

Scott, D.K. (1997). Managing organizational culture in intercollegiate athletic organizations. Quest, 4, 403-415.

Si, G., \& Lee, H. (2007). Cross-cultural issues in sport psychology research. In S. Jowett \& D. Lavallee (Eds.), Social psychology in sport (pp. 279-288). Champaign, IL: Human Kinetics.

Thomas, K.W., \& Kilmann, R.H. (2002). Thomas-Kilmann conflict mode instrument. Mountain View, CA: Consulting Psychologists Press.

Tuckman, B.W. (1965). Developmental sequence in small groups. Psychological Bulletin, 63, 384-399.

Visek, A.J., Hurst, J.R., Maxwell, J.P., \& Watson, J.C. (2008) A cross-cultural psychometric evaluation of the athletic identity measurement scale, Journal of Applied Sport Psychology, 20, 473-480.

Wujec, T. (2010, February). Build a tower, build a team [Video File]. Retrieved from https://www.ted.com/talks/tom_wujec_build_a_tower?language=en 


\section{Appendix A}

\section{Athlete, Team, Nation: Explorations in Cultures}

\section{Personal Cultural Identity \& Athletic Identity Worksheet}

Refer to the Cultural Identity and Athletic Identity Model as a framework for completing this worksheet. When you are done, you will compose a personal narrative using the following headings.

\section{Ideological Values}

- Complete the Values Card Exercise

- Where did you learn these ideological values from?

- How, if it all, might your personality have contributed to these ideological values?

\section{Sporting Values}

- What are your personal sporting values?

- Where did you learn these sporting values from?

- How, if it all, might your personality have contributed to these sporting values?

\section{Personality}

- What is your MBTI Type?

- What are your NEO-PI scores?

- In which particular facets are you very high? Very low?

- Are these assessments consistent with how you have always been?

- Are there particular individuals in your life who you believe shaped your personality?

- Are there particular events in your life that you believe shaped your personality?

\section{Sources of Cultural Values}

- What were the core values you learned from elementary school?

- What were the core values you learned from your family?

- What were the core values you learned from mainstream society?

- Were values espoused by your family and school consistent?

\section{Constraints/Enablers}

- What were some constraints that may have precluded you from participating in competitive sports?

- What were some of the factors that facilitated your being able to participate in competitive sports?

\section{Personal Sense of Cultural Identity}

- To what extent do you identify with your national culture? 
- To what extent do you identify with your family heritage?

- To what extent do you identify with a particular religion/faith?

- To what extent do you identify with being an Elon student?

- To what extent do you identify with your major/intended career?

\section{Personal Sense of Athletic Identity (prior to Elon)}

- What sports did you play growing up?

- Were there any sports that you enjoyed as much as volleyball? Why?

- Why did you choose to prioritize volleyball?

- Were there times when you considered quitting volleyball?

- What sacrifices did you make in order to play volleyball?

- What are your Athlete Identity results? What do they mean to you?

\section{Experience as a Member of the Elon Volleyball Team}

- What was it like getting acclimated to the Elon volleyball team culture?

- What was your first memory that confirmed that this was going to be a different experience for you?

- What things did you find most different about playing at Elon versus your club/HS?

- What was the hardest thing for you to get used to?

- What has been your toughest experience so far?

- How would you define your formal role on the team as a player? How would you define your role on the team as a general teammate?

- What has been your most heroic moment as an Elon volleyball player?

- What has been your biggest contribution to the team? 
- What is your favorite memory so far?

- What is one thing that you will really miss about being a member of this team? 


\section{Appendix B}

\section{Athlete, Team, Nation: Explorations in Cultures}

\section{Volleyball Team Culture Worksheet}

Complete this worksheet before Class Meeting \#3 and be prepared to discuss as a group.

- Describe the Visual Explorer Card that you selected, that best depicts the Elon volleyball team's culture.

- In no more than 2-3 sentences, summarize the Elon volleyball team culture.

- How is the volleyball team 'different' from the other Elon teams?

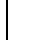

- What are the two most important team values?

- What is a sacred but unwritten rule that one should never break?

- What is a popular Elon volleyball team story that teammates talk about? Briefly explain.

- What are the processes (both formal and informal) for integrating new players into the Elon volleyball team? What sorts of things are new players shown or taught?

- You know when you are an Elon volleyball player when...

- Of your teammates, who best represents the prototypical Elon volleyball player?

- If you know of one, briefly summarize a story about a 'heroic' Elon volleyball player and what she did that made her a heroine.

- What are some of rituals and customs that are unique to the Elon volleyball team? 
- Are there any special symbols or expressions (verbal, physical, etc.) that have special meaning on the Elon volleyball team?

- What are, if there are any, subcultures within the Elon volleyball team? Describe. 


\section{Appendix C}

\section{Athlete, Team, Nation: ExPlorations in Cultures}

Volleyball Team High Performance Worksheet

Before completing this assessment, read "Team Basics: A Working Definition" taken from The Wisdom of Teams by Katzenbach \& Smith. These authors are among the foremost authorities on teams and teamwork, and have written many seminal pieces based on their experience at the prestigious McKinsey consulting firm. These consultants created their model on the basis of their observations of work teams; however, we are now using it in the context of the Elon Volleyball Team.

Complete this worksheet and be prepared to discuss in class.

TEAM DEFINED: “A small number of people with complementary skills who are committed to a common purpose, performance goals, and approach for which they hold themselves mutually accountable." (Katzenbach \& Smith, The Discipline of Teams, p. 112).

\section{SMALL NUMBER:}

1. Your team will be comprised of $\sim 15$ players.

\section{COMPLEMENTARY SKILLS:}

1. Think about the collective skills that your teammembers bring to the team. Comment on the relative strengths of the team, as well as the relative weaknesses for each of the following categories:

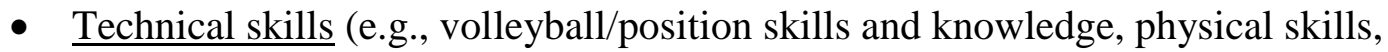
etc.)

- $\quad$ Problem-solving skills (e.g., creativity, adapting to new ideas, working collaboratively, reading game situations, improvising, resiliency, managing stress/pressure, etc.)

- Interpersonal skills (e.g., communicating, listening, building trust, managing conflict, helping, etc.)

Technical Skills:

Problem-solving Skills:

Interpersonal Skills: 


\section{COMPLEMENTARY SKILLS:}

1. In the table below, identify the greatest strength(s) and opportunity (i.e., interpersonal, technical, problem-solving) for each teammember. Provide a few words to explain your assessment (i.e., context, impact, etc.)

\begin{tabular}{|l|l|l|}
\hline Name & Greatest Strength(s) & Opportunity \\
\hline & & \\
\hline & & \\
\hline & & \\
\hline & & \\
\hline
\end{tabular}

\section{Common Purpose AND Performance Goals:}

1. What will/should be the specific performance goals for the team in 2018? Explain what the goals are, and why they are important.

2. To what extent is everyone in alignment with these goals? Do you think everyone has a clear understanding of these goals, and that everyone is fully invested in them?

\section{Common Purpose and Performance Goals:}

1. Each teammember should share with the team his/her own personal interest/goals for the project, as well as his/her thoughts on criteria for success. After everyone has shared thoughts on the team's purpose and goals, the team should create an initial charter document. This may change, particularly as you learn more about the client, so it is understood that there is a bit of brainstorming and guessing here.

A mission statement is a statement that defines the purpose of a team; it explains 'why this team exists.' A mission statement should be brief, contain powerful language, and ultimately serve as the guiding principle around which a team works. It should be inspiring and reflect the team's values and what the team wants to accomplish. Write a mission statement for your team here:

Beyond simply delivering a professional and high-quality product to the client, what might be some specific criteria for your team's success? What is it that the team is trying to achieve? 


\section{COMMON APPROACH:}

1. Apart from completing a set of tasks, effective teams operate with an agreed upon set of norms, or expectations around how people will work together in the process. This includes both coordination and management of the actual work activities as well as establishing how the members will manage interpersonal relationship during the process. Again, think about past teams you have worked on. What are some of the critical elements for how a team can most efficiently work together from a process standpoint? Consider how your team might best organize and manage itself in order to achieve its goals. Provide a suggestion for each of the following in terms of how the team might go about:

- Defining and assigning tasks

- Managing meetings

- Managing workflow

- Managing communication

- Dealing with conflict

- Other?

\section{COMMON APPROACH:}

1. Norms are agreed upon expectations for how teammembers will interact with each other. What are some of the norms that the team would like to establish to ensure maximum efficiency as well as a healthy collaborative climate? Consider the prescriptions for some of the following:

- Defining and assigning tasks

- Managing meetings

- Managing workflow

- Managing communication

- Dealing with conflict

- Other?

\section{Mutual ACCOUnTabiLity:}

1. It is assumed that each teammember will put forth substantial effort to deliver a professional and high quality product. While teammembers may complete different tasks and contribute in different ways, all should contribute equally. How might your team ensure this equality of effort? Consider:

- How might teammembers address someone who is not contributing as s/he should (i.e., missing meetings, submitting late or lower quality work, etc.)? How might they address the person if it is a consistent problem?

- How will you regulate yourself, to ensure that you are making your contributions? How will you know if you are meeting others' expectations? 


\section{MUTUAL ACCOUNTABILITY:}

1. While teammembers may complete different tasks and contribute in different ways, all should contribute equally. In the table below, identify the role(s) that each teammember will play. These roles can include work-related roles (i.e., scheduler, coordinator, notetaker, resource getter, researcher, writer, editor, presenter, etc.) as well as socio-emotional roles (i.e., leader, facilitator, energizer, encourager, questioner, brainstormer, etc.):

\begin{tabular}{|l|l|l|}
\hline Name & Task-Related Role & Socio-Emotional Role \\
\hline & & \\
\hline & & \\
\hline & & \\
\hline & & \\
\hline
\end{tabular}

2. How will teammembers go about holding each other accountable? Identify norms around how to ensure quality in each other's work and how to provide feedback to high or low performers.

3. What process will be used to ensure that the team is holding itself accountable, i.e., how it will ensure optimal quality in its final products?

\section{FOCUS ON DEVELOPMENT:}

1. According to Katzenbach $\&$ Smith, what separates a well-functioning team from a truly high performing one is teammembers' focus on their own and others' personal development. In terms of your own development, consider the following:

- Refer to your IDP and comment on your progress over the past year. To what extent did you refer to or think about your development over the past year? Explain.

- For this course, identify one competency (i.e., presenting, managing conflict, facilitating communication, delegating, etc.) that you will commit to working on during this course. What are some specific behaviors you can think of for how you can improve in this area? At the end of the course, you will receive feedback from your peers on it.

2. You will also be providing your teammembers feedback on the development objectives they identify. 